\title{
Natural radioactivity and the resulting radiation doses in some kinds of commercially marble collected from different quarries and factories in Egypt
}

\author{
S. Fares ${ }^{1 *}$, Ali. A. M. Yassene ${ }^{1}$, A. Ashour ${ }^{1}$, M. K. Abu-Assy ${ }^{2}$, \\ M. Abd El-Rahman ${ }^{1}$
}

${ }^{1}$ Department of Radiation Physics, National Center of Radiation Research and Technology NCRRT, Atomic Energy Authority, Cairo, Egypt; ${ }^{*}$ Corresponding Author: sfares2@yahoo.com

${ }^{2}$ Physics Department, Faculty of Science, Suez-Canal University, Ismailia, Egypt.

Received 21 August 2011; revised 27 September 2011; accepted 5 October 2011.

\begin{abstract}
Fourteen samples of marble were collected from different factories in Egypt. The samples were crushed, dried in controlled furnace for around twenty four hours, and then stored for five weeks in plastic Marinelli beakers. Concentrations and the $U$ - and Th-bearing minerals were studied by scanning electron microscopy (SEM) and energy dispersive X-ray spectrometry (EDS).The gamma radiation of the samples was measured, employing high resolution $y$-ray spectroscopy with an accumulating time for about 80000 sec. each. From the measured Y-ray spectra, activity concentrations were determined for marble samples ${ }^{226} \mathrm{Ra}(37.6 \pm 1.7-100.54 \pm 3.2 \mathrm{Bg} / \mathrm{kg}),{ }^{232} \mathrm{Th}(3.57$ $\pm 0.64-9.37 \pm 1.80 \mathrm{~Bq} / \mathrm{kg})$ and ${ }^{40} \mathrm{~K}(30.68 \pm 1.1$ $1196 \pm 4.9 \mathrm{~Bq} / \mathrm{kg}$ ). The absorbed dose rates, annual effective dose rates, radium equivalent activities as well as the radiation hazard indices were estimated. The radium equivalent activities $\left(R a_{\text {eq }}\right)$ are lower than the limit of $370 \mathrm{~Bq} \cdot \mathrm{kg}^{-1}$ set by the Organization for Economic Cooperation and Development (Exposure to radiation from the natural radioactivity in building materials. Report by a Group of Experts of the OECD, Nuclear Energy Agency, OECD, Paris, 1979) [1]. All obtained results referred to the fact that all the concentrations were within the allowed limits to domestic use. Comparing the results in this work with those published by International Atomic Energy Agency and local and universal researches, it was found that these concentrations were within the allowed limits for agricultural and domestic uses.
\end{abstract}

Keywords: Marble; Effective Dose; External and
Internal Hazard Indexes; NORMS; Gamma

Spectrometry; Radium Equivalent.

\section{INTRODUCTION}

Radionuclides in our environment are of three general types: primordial, cosmogenic, and anthropogenic (manmade). Natural radionuclides are present in all rocks in varying amounts depending on their concentration levels in source rock materials. It is known that the radionuclides ${ }^{238} \mathrm{U},{ }^{235} \mathrm{U}$ and ${ }^{232} \mathrm{Th}$ may become incorporated in igneous materials when they are originally formed from the molten state.

The use of building materials rich in gamma-emitting primordial radionuclides may cause substantial exposures to those inhabiting dwellings built with these products. The main products of concern are building stones, concrete, plaster and industrial by-products and residues used as ballast in building materials. The background levels in rocks from the ${ }^{238} \mathrm{U}$ and ${ }^{232} \mathrm{Th}$ series and ${ }^{40} \mathrm{~K}$ make similar contributions to the externally incident gamma radiation as the median concentrations of ${ }^{238} \mathrm{U}$, ${ }^{232} \mathrm{Th}$ and ${ }^{40} \mathrm{~K}$ in the earth $\mathrm{s}$ crust, and are typically around 35,30 and $400 \mathrm{~Bq} / \mathrm{kg}$ respectively. The use of these building materials is mostly used for floors and therefore assessment of exposure should be based on scenarios where the material is used in a typical way.

Natural building stones are made from different types of material. The radionuclide content is lowest in basic rocks of magmatic origin. Also marbles, limestone and various detrital sedimentary rocks contain only small amounts of natural radionuclides. Higher concentrations are generally found in acid magmatic rocks, especially in late-magmatic granites, and in some metamorphic rocks. In minerals the incorporation of uranium and thorium into the crystal lattice depends on the abundance of these elements in the rock during crystallization and on the 
matching of the chemical properties and the atomic radii of hosts and substitutes. Based on these general expectations the ratio of the uranium or thorium contents of individual minerals should be more or less constant. The absolute concentrations of uranium and thorium in the minerals should be related to the geochemical characteristics of the rock from which the detrital grains originate, and give an indication of their provenance [2] .

Marbles show variety of textures on account of existing minerals \& re-crystallization patterns. Texture depends upon form, size, and uniformity of grain arrangements. Marbles can be classified on the basis of the following factors:

1) Calcite Marble-Mostly $\mathrm{CaCo}_{3} ; \mathrm{MgCo}_{3}<0.50 \%$

2) Dolomite Marble_-Having $>40 \% \mathrm{MgCo}_{3}$.

3) Magnesium Marble- $\mathrm{MgCo}_{3}$ between $5 \%$ to $40 \%$.

4) Serpentine Marble-remobilised marble due to the effect of thermodynamic metamorphic wherein serpentine is prominent.

5) Onyx Marble - Lime carbonate deposition on account of cold water solution activity.

The major mineral impurities in marble (Quartz, Tremolite Actinolite, Chert, Garnet, Biotite, Muscovite, Microline, Talc, Fosterite. While the major chemical impurities in marble $\left(\mathrm{SiO}_{2}, \mathrm{Fe}_{2} \mathrm{O}_{3}, 2 \mathrm{Fe}_{2} \mathrm{O}_{3}, 3 \mathrm{H}_{2} \mathrm{O}\right.$, Limonite, Manganese, $\mathrm{Al}_{2} \mathrm{O}_{3} \cdot \mathrm{FeS}_{2}$ (pyrite). On account of the mineral composition of marble the color variations.

All building materials including marble contain various amounts of natural radioactive nuclides. Materials derived from rock and soil contain mainly natural radionuclides of the uranium ${ }^{238} \mathrm{U}$ and thorium ${ }^{232} \mathrm{Th}$ series as well as potassium ${ }^{40} \mathrm{~K}$. Marbles, in particular, exhibit an enhanced elemental concentration of these natural radionuclides in comparison to the very low abundance of these elements observed in the mantle and the crust of the Earth. The igneous rocks of marble composition are strongly enriched in $U$ and $\mathrm{Th}$ (on an average $5 \mathrm{ppm}$ of $U$ and 15 ppm of Th), compared with rocks of basaltic or ultramafic composition ( $<1$ ppm of $U$ ) [3-5]. In the ${ }^{238} U$ series, the decay chain segment starting from radium $\left({ }^{226} \mathrm{Ra}\right)$ is radiologically the most important and therefore reference is often made to ${ }^{226} \mathrm{Ra}$ instead of ${ }^{238} \mathrm{U}$. The worldwide average concentrations of ${ }^{226} \mathrm{Ra},{ }^{232} \mathrm{Th}$ and ${ }^{40} \mathrm{~K}$ in the earth's crust are about $(50,50$ and 500$) \mathrm{Bq}$ $\mathrm{kg}^{-1}$, respectively $[6,7]$.

The presence of the radioisotopes in materials causes external exposure to the people who live in the building. ${ }^{226} \mathrm{Ra}$ and ${ }^{232} \mathrm{Th}$ can also increase the concentration of ${ }^{222} \mathrm{Rn}$ and ${ }^{220} \mathrm{Rn}$ and of its daughters in the building. ${ }^{40} \mathrm{~K}$ and part of the above-mentioned radionuclides cause external exposure while the inhalation of ${ }^{222} \mathrm{Rn},{ }^{220} \mathrm{Rn}$ and their short lived progeny leads to internal exposure of the respiratory tract to alpha particles [8,9]. Any beneficial practices involving the use of radioactive materials obviously give rise to radioactive waste that, by definition, should be viewed as one aspect of the practice.

In the world, many rich marble deposits in countries like Portugal, Spain, Italy, Greece, Turkey, Iran and Pakistan are located in Alpine-Himalayan belt. As a result of its geological location, Egypt possesses very rich, natural stone reserves in various colors and patterns. Currently, Egypt has about 500 marble and granite factories. According to specialists in the industry, there are 3 types of factories: factories that are just involved in cutting the blocks into plates of marble and then distributing them to workshops that handle further cutting and polishing, factories that cut and polish the plates, and factories that do the whole process until the final product is produced. The area of "Shak El Thoban" in Katameyya has become a conglomeration of factories working in the marble and granite industry. This area was first occupied by quarrymen quarrying the limestone in the hills and mountains of Katameyya.

In order to be able to assess radiological risk, it is important to study the levels of radiation emitted from building materials. In this context, the present work aims at determining the specific activities (in $\mathrm{Bq} \cdot \mathrm{kg}^{-1}$ ) of ${ }^{226} \mathrm{Ra},{ }^{232} \mathrm{Th}$ and ${ }^{40} \mathrm{~K}$ in some Marble samples of wide use locally. In order to estimate their radiological effects, the total absorbed dose rate (D), the radium equivalent $\left(R a_{e q}\right)$, the external hazard index $\left(H_{e x}\right)$ and the internal hazard index $\left(\mathrm{H}_{\mathrm{in}}\right)$ have been estimated. Due to the health risks associated with the exposure to indoor radiation, many governmental and international bodies such as the International Commission on Radiological Protection [10], the World Health Organization, etc. have adopted strong measures aimed at minimizing such exposures. Hence, this work is important from both health and science perspectives. Even though the work cannot cover all the building material samples in Egypt, it can be a pointer for similar works if the findings are significant. It may also help adopt policies with respect to regulating the use of building materials that might be of risk to public. Authorities in areas such as Minister of Commerce and Industry and the Egypt Standards Organization can benefit from the outcome of this project.

\section{EXPERIMENTAL METHODSE}

\subsection{Samples Collection and Preparation}

A total of 14 different sample of marble tiles used in constructing houses and other buildings, were collected from different location in Egypt. These tiles, are widely used as building and ornamental materials. The samples were crushed and homogenized in grinders at the labo- 
ratory. They were then sieved through a 40-mesh sieve and then heated at $110^{\circ} \mathrm{C}$ in an oven for $24 \mathrm{~h}$ to get rid of moisture if any. The samples were then cooled and transferred to plastic Marinelli beakers of volume $500 \mathrm{ml}$ each and then properly sealed so as to keep the ${ }^{222} \mathrm{Rn}$ gas that emanate from the crushed samples to be confined to the beaker, as much as possible. The sealed Marinelli beakers were then kept for a period of 1 month to allow the short-lived progenies of ${ }^{226} \mathrm{Ra}$ and ${ }^{232} \mathrm{Th}$ to reach secular equilibrium. The radioactivity concentrations of ${ }^{226} \mathrm{Ra},{ }^{232} \mathrm{Th}$ and ${ }^{40} \mathrm{~K}$ in all of them were then determined. Fourteen samples of marble from locations were collected from different factories in Egypt. 14 samples of Marble (8 sample from Sinai, 3 sample from Suez Golf, 2 sample from Upper Egypt and one sample from Red Sea) where collected from different places in (A.R.E) as shown in Figure 1.

\subsection{Mineralogical Study}

The 14 kinds of marble used in this study are the most popular types, according to the factories that provided the samples. Selected thin sections of fresh rocks were examined by petrographic and scanning electron microscopy \{SEM micrographs were obtained with a JSM-
5400 (Jeol/Japan) $\}$. Fracture surfaces were obtained by compression of the specimens. Surface of fracture was sputtered with thin layer of gold. Minerals were analyzed by Energy Dispersive Spectrometry (EDS) at National Center of Radiation Research and Technology NCRRT, Atomic Energy Authority, Cairo, Egypt. For XRD analysis, X-Ray Diffraction patterns were obtained with XRD_-DI series, Shimadzu apparatus using $\mathrm{Ni}-$ filter and $\mathrm{Cu}-\mathrm{K}$ target.

\subsection{Gamma Spectrometric Analysis}

The HPGe detector had a relative efficiency of $30 \%$ and full width at half maximum (FWHM) of $1.89 \mathrm{keV}$ for the $1332 \mathrm{keV} \gamma$-ray line of ${ }^{60} \mathrm{Co}$. The detector was surrounded by a special heavy lead shield of about 10 $\mathrm{cm}$ thickness with inside dimensions $28 \mathrm{~cm}$ diameter $40.5 \mathrm{~cm}$ high to reduce background radiation originating from building materials and cosmic rays. The spectrometer was calibrated using both uranium nitrate source and potassium chloride standard sources in the same geometry as the samples. A set of high quality certified reference materials (IAEA, RG-set) was used. The analysis of output spectrum was carried out with the help of Canberra Genie 2000 software version 3.0.

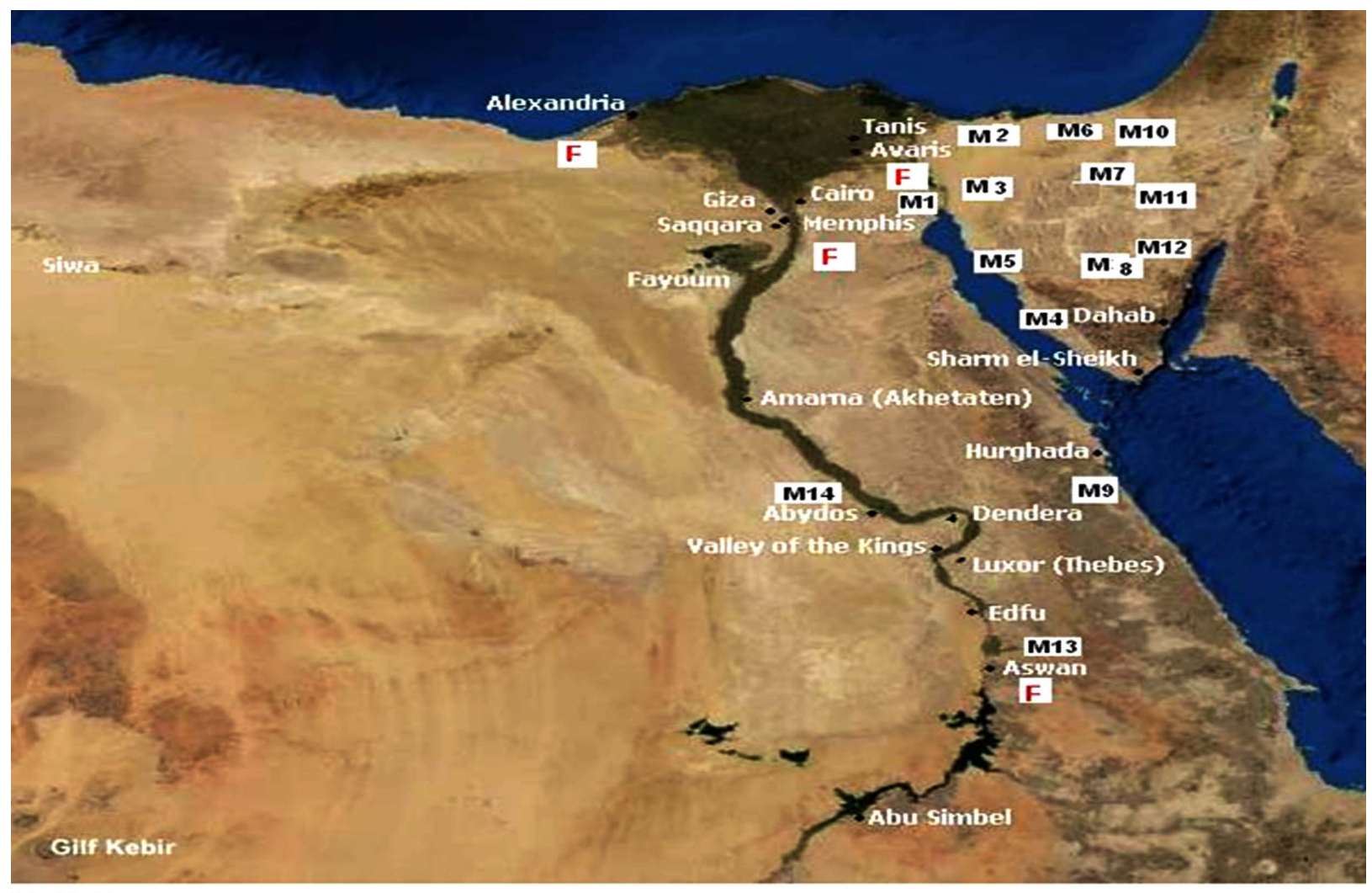

M - Marble

F - Factories of Marble

Figure 1. Location of marble quarries and factories in Egypt. 
The ${ }^{226} \mathrm{Ra}$ activities (or ${ }^{238} \mathrm{U}$ activities for samples assumed to be in radioactive equilibrium) were estimated from ${ }^{214} \mathrm{~Pb}(351.9 \mathrm{keV}),{ }^{214} \mathrm{Bi}(609.3,1764.5 \mathrm{keV})$ and ${ }^{226} \mathrm{Ra}(185.99 \mathrm{KeV})$. Several ${ }^{214} \mathrm{~Pb}$ and ${ }^{214} \mathrm{Bi}$ peaks were also monitored. The Gamma ray energies of ${ }^{212} \mathrm{~Pb}(238.6$ $\mathrm{keV})$ and ${ }^{228} \mathrm{Ac}(338.4,911.07,968.90 \mathrm{keV})$ were used to estimate the concentration of ${ }^{232} \mathrm{Th}$. The natural abundance of ${ }^{235} \mathrm{U}$ is only $0.72 \%$ of the total uranium content and hence was not considered in the present study. The activity concentrations of ${ }^{40} \mathrm{~K}$ were measured directly by its own gamma rays $(1460.8 \mathrm{keV})$. The activity concentrations were calculated from the intensity of each line taking into account the mass of the sample, the branching ratios of the $\gamma$-decay, the time of counting and the efficiencies of the detector. The activity concentrations of the investigated samples were calculated from Eq.1:

$$
\mathbf{A}_{\mathrm{Ei}}=\mathbf{N}_{\mathrm{Ei}} / \varepsilon_{\mathrm{E}} \mathbf{t} \gamma_{\mathrm{d}} \mathbf{M}_{\mathrm{s}}
$$

where $\mathbf{N}_{\mathbf{E i}}$ is the Net Peak Area of a peak at energy E, $\boldsymbol{\varepsilon}_{\mathbf{E}}$ is the detection efficiency at energy $E, t$ is the counting lifetime, $\gamma_{d}$ is the number of gammas per disintegration of this nuclide for a transition at energy $\mathrm{E}$, and $\mathbf{M}_{\mathbf{s}}$ is the mass in $\mathrm{kg}$ of the measured sample. If there is more than one peak in the energy analysis range for a nuclide, then an attempt to average the peak activities is made. The result is then the weighted average nuclide activity. The correction for the contribution of ${ }^{232} \mathrm{Th}$ via its daughter nuclide ${ }^{228} \mathrm{Ac}$ (1459.2 keV peak) to the $1460.8 \mathrm{keV}$ peak of ${ }^{40} \mathrm{~K}$ was made according to [11]

The error in

$$
{ }^{40} \mathbf{K} \text { activity }(\%)=9.3\left(\mathbf{A}_{\text {Th }} / \mathbf{A}_{\mathbf{K}}\right)
$$

Activity concentrations, calculated from the intensity of several $\gamma$-rays emitted by a nuclide, are grouped together to produce a weighted average activity per nuclide. Errors arise due to a number of factors, like efficiency calibrations, peak area determination and random uncertainties associated with background and sample counts. Each sample was measured during an accumulating time between 20 and $24 \mathrm{~h}$ in the Laboratory of Atomic and Nuclear Physics, Department of Physics, Suez Canal University. After each sample counting, an empty cylindrical plastic container was placed in the detection system, during a counting period of $24 \mathrm{~h}$, in order to collect the background count rates.

\subsection{Assessment of Radiological Risk}

In order to assess the radiological impact of marble used as building materials, the model of a rectangular parallel lepipedon house building $(3 \mathrm{~m} \times 3 \mathrm{~m} \times 3 \mathrm{~m})$, with infinite thin walls and no doors and windows (standard room model) was commonly considered [6].
The absorbed gamma dose rate in air $1 \mathrm{~m}$ above the ground surface for the uniform distribution of radionuclides $\left({ }^{238} \mathrm{U},{ }^{232} \mathrm{Th}\right.$ and $\left.{ }^{40} \mathrm{~K}\right)$ was computed on the basis of guidelines provided by UNSCEAR $(1993,2000)[6,7]$. The conversion factors used to compute absorbed gamma dose rate (D)in air per unit activity concentration in $\left(1 \mathrm{~Bq} \cdot \mathrm{kg}^{-1}\right)$ samples correspond to $0.621 \mathrm{nGyh}^{-1}$ for ${ }^{232} \mathrm{Th}$, $0.462 \mathrm{nGyh}^{-1}$ for ${ }^{238} \mathrm{U}$, and $0.0417 \mathrm{nGyh}^{-1}$ for ${ }^{40} \mathrm{~K}$ [12]:

$$
\mathbf{D}=\left(\mathbf{0 . 6 2 1} \mathrm{A}_{\mathrm{Th}}+\mathbf{0 . 4 6 2} \mathrm{A}_{\mathrm{Ra}}+\mathbf{0 . 0 4 1 7} \mathrm{A}_{\mathrm{K}}\right) \mathbf{n G y} \cdot \mathbf{h}^{-1} \text { (3) }
$$

where, $A_{T h}, A_{R a}$ and $A_{K}$ represent the average activity concentrations of ${ }^{232} \mathrm{Th},{ }^{226} \mathrm{Ra}$ and ${ }^{40} \mathrm{~K}$ in $\mathrm{Bq} \cdot \mathrm{kg}^{-1}$, respectively.

Finally, in order to make a rough estimate for the annual effective dose outdoors, one has to take into account the conversion coefficient from absorbed dose in air to effective dose and the outdoor occupancy factor. In the UNSCEAR recent reports [6,7], the Committee used 0.7 $\mathrm{Sv} \cdot \mathrm{Gy}^{-1}$ for the conversion coefficient from absorbed dose in air to effective dose received by adults, and 0.2 for the outdoor occupancy factor. Annual effective dose rate outdoors in units of $\mu \mathrm{Sv}$ per year is calculated by the following formula:

$$
\begin{aligned}
\operatorname{AEDR}(\text { Indoor })= & \text { dose rate }\left(\text { in } \mathbf{n G y} \cdot \mathbf{h}^{-1}\right) \times 24 \mathrm{~h} \\
& \times 365.25 \mathrm{~d} \times \mathbf{0 . 8} \\
& \times 0.7 \mathrm{SvGy}^{-1} \times 10^{-6} \\
\operatorname{AEDR}(\text { Outdoor })= & \text { dose rate }\left(\mathrm{in} \mathbf{n G y} \cdot \mathrm{h}^{-1}\right) \times \mathbf{2 4} \mathrm{h} \\
& \times 365.25 \mathrm{~d} \times \mathbf{0 . 2} \\
& \times \mathbf{0 . 7} \mathrm{SvGy}^{-1} \times \mathbf{1 0}^{-6}
\end{aligned}
$$

According to most recent regulations and especially the recommendation No. 112 issued by the European Union in 1999 [13], building materials should be exempted from all restrictions concerning their radioactiveity, if the excessive gamma radiation due to those materials causes the increase of the annual effective dose received by an individual by a maximum value of 0.3 $\mathrm{mSv}$. Effective doses exceeding the dose criterion of 1 $\mathrm{mSv} \cdot \mathrm{y}^{-1}$ should be taken into account in terms of radiation protection. It is therefore recommended that controls should be based on a dose range of $0.3-1.0 \mathrm{mSv} \cdot \mathrm{y}^{-1}$, which is the building material gamma dose contribution to the dose received outdoors.

Marbles are widely used in the building construction that includes tiling, ornamental and covering both for exterior and interior use. In order to assess the radiation hazard associated with the building materials used, the Raeq have been evaluated, where it is assumed that all the decay products of ${ }^{226} \mathrm{Ra}$ and ${ }^{232} \mathrm{Th}$ are in radioactive equilibrium with their precursors. The Raeq is calculated according to the following formula $[14,15]$ :

$$
\mathbf{R a}_{\mathrm{eq}}=\mathbf{A}_{\mathrm{Ra}} \mathbf{1 . 4 3}+\mathbf{A}_{\mathrm{Th}}+\mathbf{0 . 0 7 7} \mathbf{A}_{\mathrm{K}}
$$

where $\mathbf{A}_{\mathbf{R a}}, \mathbf{A}_{\mathrm{Th}}$ and $\mathbf{A}_{\mathbf{K}}$ are The activity concentrations $\left(\mathrm{Bq} \cdot \mathrm{kg}^{-1}\right)$ of ${ }^{226} \mathrm{Ra},{ }^{232} \mathrm{Th}$ and ${ }^{40} \mathrm{~K}$, respectively. This 
formula is based on the estimation that $1 \mathrm{~Bq} \cdot \mathrm{kg}^{-1}$ of ${ }^{238} \mathrm{U}$, $0.7 \mathrm{~Bq} \cdot \mathrm{kg}^{-1}$ of ${ }^{232} \mathrm{Th}$ and $13 \mathrm{~Bq} \cdot \mathrm{kg}^{-1}$ of ${ }^{40} \mathrm{~K}$ produce the same gamma-ray dose rates.

To estimate the gamma-radiation dose expected to be delivered externally from building materials, a model was suggested by various researchers to limit the radiation dose from building materials to $1.5 \mathrm{mSv} \cdot \mathrm{y}^{-1}$. In this model the external hazard index has been defined $\left(\mathbf{H}_{\mathbf{e x}}\right)$ defined by some workers $[15,16]$ :

$$
\mathbf{H}_{\mathrm{ex}}=\mathbf{A}_{\mathrm{Ra}} / \mathbf{3 7 0}+\mathbf{A}_{\mathrm{Th}} / \mathbf{2 5 9}+\mathbf{A}_{\mathrm{K}} / 4810
$$

The radiation risk is negligible when the maximum value of the external hazard index is less than unity $\left(\mathbf{H}_{\mathbf{e x}}\right.$ $\leq 1$ ), which is equivalent to a maximum value of the Raeq activity $<370 \mathrm{~Bq} \cdot \mathrm{kg}^{-1}$. In terms of dose equivalent, this index must be less than unity so that the annual effective dose due to radioactivity in the material will be $\leq$ $1.5 \mathrm{mSv} \cdot \mathrm{y}^{-1}$.

Internal exposures arise from the inhalation of radon $\left({ }^{222} \mathrm{Rn}\right)$ gas and its short-lived decay products as well as from the inhalation or ingestion of other radionuclides. Radon is part of the radioactive series of ${ }^{238} \mathrm{U}$, which is present in building materials. To assess the internal exposure to ${ }^{222} \mathrm{Rn}$ gas, the internal hazard index has been defined as [15]:

$$
\mathbf{H}_{\text {in }}=\mathbf{A}_{\mathrm{Ra}} / \mathbf{3 7 0}+\mathbf{A}_{\mathrm{Th}} / \mathbf{2 5 9}+\mathbf{A}_{\mathrm{K}} / 4810
$$

The use of a material in the construction of dwellings is considered safe when the maximum value of the internal hazard index is less than unity $\left(\mathbf{H}_{\mathbf{i n}} \leq 1\right)$, As the marble are widely used as building and covering materials, it is also possible to use an activity utilization index, proposed by [ 7 and/or 13], that facilitates the derivation of dose rates in air from different combinations of these three radio nuclides [17].

According to the EC, the following gamma activity concentration index $\left(\mathbf{I}_{\boldsymbol{\gamma} \mathbf{r}}\right)$ (representative level index) is derived for identifying whether a dose criterion is met:

$$
\mathbf{I}_{\gamma \mathrm{r}}=\mathbf{A}_{\mathrm{Ra}} / \mathbf{1 5 0}+\mathbf{A}_{\mathrm{Th}} / \mathbf{1 0 0}+\mathbf{A}_{\mathrm{K}} / \mathbf{1 5 0 0}
$$

The index $I_{\gamma_{\mathrm{r}}}$ is correlated with the annual dose due to the excess external gamma radiation caused by superficial material. Values of index $\mathrm{I} \leq 1$ correspond to 0.3 $\mathrm{mSv} / \mathrm{y}$, while $\mathrm{I} \leq 3$ correspond to $1 \mathrm{mSv} / \mathrm{y}$. Thus, the activity concentration index should be used only as a screening tool for identifying materials which might be of concern to be used as covering material. According to this dose criterion, materials with $\mathrm{I} \leq 3$ should be avoided, since these values correspond to dose rates higher than $1 \mathrm{mSv} / \mathrm{y}$ [13] which is the highest value of dose rate in air recommended for population [6,7].

Due to radon inhalation originating from building materials [13]. The alpha index was determined using the following formula:

$$
\mathbf{I}_{\alpha}=\mathbf{A}_{\mathrm{Ra}} / \mathbf{2 0 0}\left(\mathbf{B q} \cdot \mathbf{k g}^{-1}\right)
$$

where $\mathbf{A}_{\mathbf{R a}}\left(\mathrm{Bq} \cdot \mathrm{kg}^{-1}\right)$ is the activity concentration of ${ }^{226} \mathrm{Ra}$ assumed in equilibrium with ${ }^{238} \mathrm{U}$. The recommended exemption and upper level of ${ }^{226} \mathrm{Ra}$ activity concentrations in building materials are 100 and $200 \mathrm{~Bq} \cdot \mathrm{kg}^{-1}$, respectively, as suggested by ICRP [10]. These considerations are reflected in the alpha index. The recommended upper limit concentration of ${ }^{226} \mathrm{Ra}$ is $200 \mathrm{~Bq} \cdot \mathrm{kg}^{-1}$, for which $\mathbf{I}_{\alpha}=1$.

\section{RESULTS AND DISCUSSION}

Table 1 presents the various ${ }^{226} \mathrm{Ra},{ }^{232} \mathrm{Th}$ and ${ }^{40} \mathrm{~K}$ activity concentrations and their associated absorbed dose rates and annual effective dose rates for the 14 Marble samples under investigation. The radioactivity concentration values in the selected Marble samples ranged from $(3.57 \pm 0.64)$ to $(9.37 \pm 1.8) \mathrm{Bq} \cdot \mathrm{kg}^{-1}$ for ${ }^{232} \mathrm{Th}$,

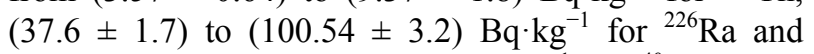
$(30.68 \pm 1.1)$ to $(1196 \pm 4.9) \mathrm{Bq} \cdot \mathrm{kg}^{-1}$ for ${ }^{40} \mathrm{~K}$. It was clearly evident that ${ }^{40} \mathrm{~K}$ always contributed to the most specific activity compared with ${ }^{232} \mathrm{Th}$ and ${ }^{226} \mathrm{Ra}$. The sample M14 presented the lowest activity concentrations for ${ }^{232} \mathrm{Th}$ and ${ }^{226} \mathrm{Ra}$, whereas it presented the highest activity value for ${ }^{40} \mathrm{~K}$. All samples have ${ }^{40} \mathrm{~K}$ activity concentrations lower than the regular soil values, except sample M14 with activity concentrations higher than double those of the regular soil values of $1196 \mathrm{~Bq} / \mathrm{Kg}$. Moreover samples M4, M8 and M9 have ${ }^{226} \mathrm{Ra}$, activeity concentrations higher more than double those of the regular soil concentrations. The measured minimum, maximum and mean activity concentration values, together with the statistical uncertainty $\left(1_{\sigma}\right)$ and standard deviation (SD), of the above natural radionuclides are presented for the different regions in Table 1. Figure 2 shows a comparison of concentration for ${ }^{226} \mathrm{Ra},{ }^{232} \mathrm{Th}$ and ${ }^{40} \mathrm{~K}\left(\mathrm{~Bq} \cdot \mathrm{kg}^{-1}\right)$.

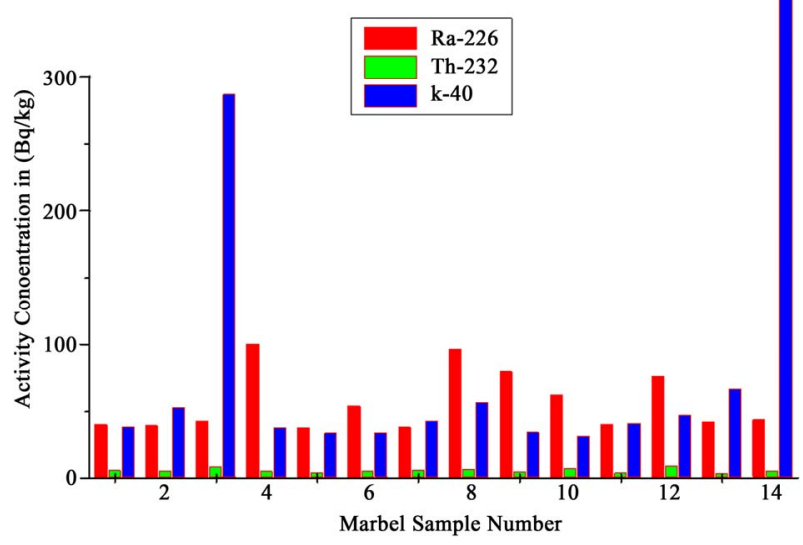

Figure 2. Histogram comparing the activity concentration ${ }^{226} \mathrm{Ra},{ }^{232} \mathrm{Th}$ and ${ }^{40} \mathrm{~K}$. 
Table 1. ${ }^{226} \mathrm{Ra},{ }^{232} \mathrm{Th}$ and ${ }^{40} \mathrm{~K}$ activity concentrations $\left(\mathrm{Bq} \cdot \mathrm{kg}^{-1}\right)$, absorbed dose rate $\left(\mathrm{nGy} \cdot \mathrm{h}^{-1}\right)$ and annual effective dose rate (indooroutdoor) $\left(\mathrm{mSv} \cdot \mathrm{y}^{-1}\right)$ for different marble samples.

\begin{tabular}{|c|c|c|c|c|c|c|c|}
\hline Sample name & Region & $\begin{array}{c}{ }^{226} \mathrm{Ra} \\
\left(\mathrm{Bq} \cdot \mathrm{kg}^{-1}\right)\end{array}$ & $\begin{array}{c}{ }^{232} \mathbf{T h} \\
\left(\mathrm{Bq} \cdot \mathrm{kg}^{-1}\right)\end{array}$ & $\left({ }^{40} \mathrm{~K} \cdot \mathrm{kg}^{-1}\right)$ & $\begin{array}{c}\text { Absorbed Dose Rate D } \\
\left(\mathrm{nGy} \cdot \mathrm{h}^{-1}\right)\end{array}$ & $\begin{array}{c}\text { AEDR (outdoor) } \\
\left(\mathbf{m S v} \cdot \mathbf{y}^{-1}\right)\end{array}$ & $\begin{array}{c}\text { AEDR (indoor) } \\
\left(\mathbf{m S v} \cdot \mathbf{y}^{-1}\right)\end{array}$ \\
\hline M1 & Suez Golf & $39.86 \pm 3.1$ & $5.94 \pm 0.5$ & $38.16 \pm 1.3$ & 23.70 & 0.03 & 0.12 \\
\hline M2 & Sinai & $39.10 \pm 1.5$ & $5.52 \pm 1.2$ & $53.04 \pm 0.9$ & 23.71 & 0.03 & 0.12 \\
\hline M3 & Sinai & $43.03 \pm 2.8$ & $8.85 \pm 1.9$ & $286.68 \pm 0.5$ & 37.33 & 0.05 & 0.18 \\
\hline M4 & Suez Golf & $100.54 \pm 3.2$ & $5.24 \pm 1.4$ & $37.56 \pm 1.5$ & 51.27 & 0.06 & 0.25 \\
\hline M5 & Suez Golf & $37.6 \pm 1.7$ & $4.36 \pm 1.02$ & $33.4 \pm 2.1$ & 21.47 & 0.03 & 0.11 \\
\hline M6 & Sinai & $54.47 \pm 3.9$ & $5.6 \pm 1.11$ & $33.8 \pm 1.4$ & 30.05 & 0.04 & 0.15 \\
\hline M7 & Sinai & $37.76 \pm 1.6$ & $5.97 \pm 1.3$ & $43.28 \pm 0.7$ & 22.96 & 0.03 & 0.11 \\
\hline M8 & Sinai & $96.46 \pm 4.4$ & $6.88 \pm 1.21$ & $57 \pm 1.3$ & 51.21 & 0.06 & 0.25 \\
\hline M9 & Red Sea & $79.99 \pm 2.1$ & $5.03 \pm 0.84$ & $34.12 \pm 1.5$ & 41.50 & 0.05 & 0.20 \\
\hline M10 & Sinai & $62.51 \pm 2.5$ & $7.53 \pm 0.93$ & $30.68 \pm 1.1$ & 34.85 & 0.04 & 0.17 \\
\hline M11 & Sinai & $40.15 \pm 3.5$ & $3.91 \pm 0.95$ & $40.8 \pm 1.4$ & 22.68 & 0.03 & 0.11 \\
\hline M12 & Sinai & $76.49 \pm 1.3$ & $9.37 \pm 1.80$ & $47.4 \pm 1.7$ & 43.13 & 0.05 & 0.21 \\
\hline M13 & Aswan & $42.66 \pm 1.1$ & $3.57 \pm 0.64$ & $66.92 \pm 2.8$ & 24.72 & 0.03 & 0.12 \\
\hline M14 & Qena & $44.26 \pm 2.3$ & $5.57 \pm 1.50$ & $1196 \pm 4.9$ & 73.78 & 0.09 & 0.36 \\
\hline Average & Average & $56.78 \pm 2.5$ & $5.95 \pm 1.2$ & $142.8 \pm 1.7$ & 35.88 & 0.044 & 0.18 \\
\hline $\begin{array}{l}\text { Regular soil } \\
\text { (global scale) }^{*}\end{array}$ & $\begin{array}{l}\text { Regular soil } \\
\text { (global scale) }\end{array}$ & 35 & 30 & 400 & 55 & $0.3-1.0$ & $0.3-1.0$ \\
\hline
\end{tabular}

*Regular Soil (global scale) from UNSCEAR(2000).

The absorbed dose rates (D) indoor air calculated from the measured activities in marble samples are also given in Table 1. For the different marble types and the regions from where they were collected. The absorbed dose rates indoor air were found to vary from 21.47 to $73.78 \mathrm{nGy} \cdot \mathrm{h}^{-1}$ with a mean value of $35.88 \mathrm{nGy} \cdot \mathrm{h}^{-1}$.

Average absorbed dose rates for all samples are lower than the world average value of $55 \mathrm{nGy} / \mathrm{h}$ [7], except for M14 sample. Studies indicate an average outdoor terrestrial gamma dose rate of $60 \mathrm{nGy} / \mathrm{h}$ in the world ranging from 10 to $200 \mathrm{nGy} / \mathrm{h}$ [18]. From the present work we found that the average terrestrial gamma dose rate is $35.88 \mathrm{nGy} / \mathrm{h}$ which is lower than the world average.

The calculated AEDR (outdoor and indoor) values are given in Table 1. The minimum, the maximum and the average values for outdoor are $0.03 \mathrm{mSv} / \mathrm{y}, 0.09 \mathrm{mSv} / \mathrm{y}$ and $0.044 \mathrm{mSv} / \mathrm{y}$, respectively and the corresponding indoor values are $0.11 \mathrm{mSv} / \mathrm{y}, 0.36 \mathrm{mSv} / \mathrm{y}$ and 0.18 $\mathrm{mSv} / \mathrm{y}$ respectively.

The Raeq is related to the external gamma dose and the internal dose due to radon and its daughters [15]. In the present work, Raeq was estimated for the investigated samples and are given in Table 2. The highest value of radium equivalent in marble is $144.32(\mathrm{~Bq} / \mathrm{kg})$. It is observed that the calculated radium equivalent for all samples are lower than the recommended maximum value $370 \mathrm{~Bq} / \mathrm{kg}$. As reference The world average permissible dose limit for public which is recommended by ICRP [10] is $1.5 \mathrm{mSv} \cdot \mathrm{y}^{-1}$ which equivalent to 370 $\mathrm{Bq} \cdot \mathrm{kg}^{-1}$.

The values of the $\left(\mathrm{H}_{e x}, \mathrm{H}_{i n}\right)$ indices must be less than unity for the radiation risk to be negligible [16]. For the maximum value of $\mathrm{H}_{e x}$ to be less than unity, the maximum value of Raeq must be less than $370 \mathrm{~Bq} / \mathrm{kg}$. This is the radiation exposure due to the radioactivity from a construction material, limited to $1.5 \mathrm{mGyyr}^{-1}$. The maximum values of Hin equal to unity corresponds to the upper limit of $\mathrm{Ra}_{e q}\left(370 \mathrm{~Bq} \cdot \mathrm{kg}^{-1}\right)$. The values of $\mathrm{H}_{e x}$ for the studied marble samples range from 0.13 to 0.39 , with an average value of 0.21 , are less than unity, Table 2 .

The mean internal radiation hazard index $\mathrm{H}_{\text {in }}$ is for the studied marble samples is 0.36 (Table 2). The external and internal radiation hazard indices are less then 1, which means it is safe for human to carry out their activities in the area.

The mean values of $\mathrm{I}_{\gamma}$ calculated from the measured activity concentrations of ${ }^{226} \mathrm{Ra},{ }^{232} \mathrm{Th}$ and ${ }^{40} \mathrm{~K}$ are presented in Table 2 for different marble types and the regions from where they were collected. The calculated values of $\left(\mathrm{I}_{\gamma}\right)$ for the studied samples varied in the range between $0.32-1.15$ for marble types are lower than the unity (except for M14), $\mathrm{I}_{\gamma}<1$ corresponds to a dose 
creation of $1 \mathrm{mSv} \cdot \mathrm{y}^{-1}$, while $\mathrm{I}_{\gamma}<0.5$ corresponds to 0.3 $\mathrm{mSv} \cdot \mathrm{y}^{-1}$. It is clear form in Table 2 that the mean value of the activity index $\mathrm{I}_{\gamma}$ is 0.53 , which is less than the upper limit for $\mathrm{I}_{\gamma}<0.5$. The mean computed $\mathrm{I}_{\alpha}$ values for the studied samples are given in Table 2 for the different marble sample and the regions where they were collected. The values of $I_{\alpha}$ ranged from $(0.19$ to 0.5$)$, with the mean value of 0.28 for the safe use of a material in the construction of dwellings, $\mathrm{I}_{\alpha}$ should be less than unity.

Table 3 compares the reported values of natural radioactivity for marble obtained in other published data with those determined in this study. As shown in this table, the radioactivity in marble samples varied from one country to another. It is important to point out that these values were not the representative values for the countries mentioned but for the regions from where the samples were collected. The values of the radionuclides concentration for all the selected marble samples in present study were in the same range of the corresponding material in other published data except in some samples. As shown in Table 3 the values of radium equivalent obtained for present materials are found to be higher compared to that of other countries.

Table 2. Calculated raeq $\left(\mathrm{Bq} \cdot \mathrm{kg}^{-1}\right), H_{\mathrm{ex}}$ and $H_{\text {in }}$ indices, gamma alpha indices $\left(\mathrm{I}_{\gamma}, \mathrm{I}_{\alpha}\right)$ for marble samples.

\begin{tabular}{|c|c|c|c|c|c|}
\hline Sample name & $\mathrm{Ra}_{\mathrm{eq}}\left(\mathrm{Bq} \cdot \mathrm{kg}^{-1}\right)$ & $H_{\text {in }}$ & $H_{\text {ex }}$ & $\mathrm{I}_{\gamma}<1$ & $\mathrm{I}_{\alpha}<1$ \\
\hline M1 & 51.30 & 0.25 & 0.14 & 0.35 & 0.20 \\
\hline M2 & 51.08 & 0.24 & 0.14 & 0.35 & 0.20 \\
\hline M3 & 77.76 & 0.33 & 0.21 & 0.57 & 0.22 \\
\hline M4 & 110.93 & 0.57 & 0.30 & 0.75 & 0.50 \\
\hline M5 & 46.41 & 0.23 & 0.13 & 0.32 & 0.19 \\
\hline M6 & 65.08 & 0.32 & 0.18 & 0.44 & 0.27 \\
\hline M7 & 49.63 & 0.24 & 0.13 & 0.34 & 0.19 \\
\hline M8 & 110.69 & 0.56 & 0.30 & 0.75 & 0.48 \\
\hline M9 & 89.81 & 0.46 & 0.24 & 0.61 & 0.40 \\
\hline M10 & 75.67 & 0.37 & 0.20 & 0.51 & 0.31 \\
\hline M11 & 48.88 & 0.24 & 0.13 & 0.33 & 0.20 \\
\hline M12 & 93.54 & 0.46 & 0.25 & 0.64 & 0.38 \\
\hline M13 & 52.92 & 0.26 & 0.25 & 0.36 & 0.21 \\
\hline M14 & 144.32 & 0.51 & 0.39 & 1.15 & 0.22 \\
\hline Average & 76.29 & 0.36 & 0.21 & 0.53 & 0.28 \\
\hline
\end{tabular}

Table 3. Comparison of radionuclides concentrations $\left(\mathrm{Bq} \cdot \mathrm{kg}^{-1}\right)$ and $\mathrm{Ra}_{\mathrm{eq}}\left(\mathrm{Bq} \cdot \mathrm{kg}^{-1}\right)$ in Marble Samples with those obtained in other published data.

\begin{tabular}{|c|c|c|c|c|c|c|}
\hline Country/region & Material & ${ }^{226} \mathrm{Ra}\left(\mathrm{Bq} \cdot \mathrm{kg}^{-1}\right)$ & ${ }^{232} \mathrm{Th}\left(\mathrm{Bq} \cdot \mathrm{kg}^{-1}\right)$ & ${ }^{40} \mathrm{~K}\left(\mathrm{~Bq} \cdot \mathrm{kg}^{-1}\right)$ & $\operatorname{Ra}_{\mathrm{eq}}\left(\mathrm{Bq} \cdot \mathrm{kg}^{-1}\right)$ & Ref. \\
\hline Egypt & Marble tiles & $56.78 \pm 2.5$ & $5.95 \pm 1.2$ & $142.8 \pm 1.7$ & 76.29 & Presen work \\
\hline Algerian & Marble chips & $23 \pm 2$ & $18 \pm 2$ & $310 \pm 3$ & $73 \pm 4.1$ & Amrani and Tahtat(2001) \\
\hline Cameroonian & $\begin{array}{c}\text { Marbles } \\
\text { (by-products) }\end{array}$ & $8 \pm 2$ & $0.35 \pm 0.02$ & $19 \pm 2$ & 10.15 & M.Ngachin et al. (2007) [20] \\
\hline Jordan( Azraq) & $\begin{array}{c}\text { Marbles } \\
\text { (by-products) }\end{array}$ & 20.1 & 11.4 & 85 & 42.9 & $\begin{array}{l}\text { Ahmed and Hussein (1997) } \\
\text { [21] }\end{array}$ \\
\hline Kuwait & $\begin{array}{c}\text { Marbles } \\
\text { (by-products) }\end{array}$ & $3.9 \pm 0.5$ & $0.22 \pm 0.08$ & $3.7 \pm 0.5$ & 4.2 & $\begin{array}{c}\text { Bou-Rabee and Bem (1996) } \\
\text { [22] }\end{array}$ \\
\hline Egypt (Qena) & $\begin{array}{c}\text { Marbles } \\
\text { (by-products) }\end{array}$ & $205 \pm 83$ & $115 \pm 60$ & $865 \pm 392$ & - & Ahmed (2005) [23] \\
\hline Saudi Arabia & $\begin{array}{c}\text { Marbles } \\
\text { (by-products }\end{array}$ & $\begin{array}{ll}12.0 & 0.2\end{array}$ & $\begin{array}{ll}1.7 & 0.1\end{array}$ & $23.1 \quad 0.1$ & 16.21 & Fardous et al. (2007) [24] \\
\hline
\end{tabular}




\section{Elemental Analysis's of Material}

Chemical composition of samples shows in Table 4 which forgets by using analysis (EDEX). The samples marble $\mathrm{M}$ arrangement by increase the $(\mathrm{Ca})$ element. Major element composition of the marble $\mathrm{M}$ are quite similar, but calc alkaline rocks are slightly richer in $\mathrm{Fe}$, $\mathrm{Mg}$ and $\mathrm{Ca}$. Potassium feldspar is commonly microcline and plagioclases are mainly sodic (i.e. albite and oligoclase). Quartz contents are similar, mica abundance is variable, and biotite dominates over muscovite. The latter can be considered as an accessory mineral in some of the analyzed rocks. The ESEM is used to investigate the semi-quantitative of the elemental composition for this region. It can be observed that in all of them, $\mathrm{Ca}$ is the predominant, followed by $\mathrm{Na}, \mathrm{Mg}$. The $\mathrm{M}(10,12,13$ 14) are characterized by appear Ti and $\mathrm{M}(12,13,14)$ appear $\mathrm{K}$ meanwhile disappear in other samples. In sample $\mathrm{M}$ (14) presents a significant amount of iron. The ESEM analysis was made for the selected spot in sample No (14) and the obtained results are shown in Table 4.

The chemical composition of the Marble samples are summarized in Table 4. As the U and Th elemental concentrations $(\mathrm{mg} / \mathrm{kg})$ are below the detection limit of the system used, the activity concentrations of ${ }^{226} \mathrm{Ra}$ and ${ }^{232} \mathrm{Th}\left(\mathrm{Bq} \cdot \mathrm{kg}^{-1}\right)$ are measured using gamma spectrometry. Then, elemental concentrations of $\mathrm{U}, \mathrm{Th}$ and $\mathrm{K}$ were calculated using ${ }^{226} \mathrm{Ra},{ }^{232} \mathrm{Th}$ and ${ }^{40} \mathrm{~K}\left(\mathrm{~Bq} \cdot \mathrm{kg}^{-1}\right)$ activity concentrations, respectively [25] Calculated values are presented in Table 4 in units of ppm. Since Th and U elements are considered because of radioactive toxicity, it is important to check if they are above the international levels or not. Permissible concentrations of Th and $\mathrm{U}$ in the building materials should not exceed the internationally accepted levels of 20 and $10 \mathrm{mg} / \mathrm{kg}$, respecttively [26]. The mean obtained values for Th and $U$ are within the international accepted values in general.

Table 4. Chemical composition of marble samples.

\begin{tabular}{|c|c|c|c|c|c|c|c|c|c|}
\hline Region & Commercial name, Element & $\mathrm{Cu}$ & $\mathrm{Fe}$ & $\mathrm{Ti}$ & $\mathrm{Ca}$ & $\mathrm{Cl}$ & $\mathrm{S}$ & $\mathrm{Si}$ & $\mathrm{Al}$ \\
\hline Suez Golf & Glalla ElSuez M1 & 0.89 & - & - & 97.83 & 0.03 & 0.06 & - & 0.13 \\
\hline Sinai & Alpastar Odysyi M2 & 0.33 & 0.04 & - & 94.61 & 0.01 & 0.06 & 0.07 & 0.04 \\
\hline Sinai & AswadPrown M3 & 0.05 & 0.35 & - & 93.76 & 0.03 & 0.15 & 0.46 & 0.37 \\
\hline Suez Golf & Glalla KasKremy M4 & 0.40 & 0.00 & - & 93.49 & 0.08 & 0.12 & 0.09 & 0.15 \\
\hline Suez Golf & Red Glalla M5 & 1.18 & 0.18 & - & 93.24 & 0.04 & 0.05 & 0.21 & 0.16 \\
\hline Sinai & Prechaa M6 & 0.29 & 0.49 & - & 92.74 & 0.07 & 0.06 & 0.47 & 0.19 \\
\hline Sinai & Khatemaa M7 & 0.29 & 0.49 & - & 91.95 & 0.10 & 0.08 & 2.01 & 0.58 \\
\hline Sinai & Kerstin M8 & 0.28 & 0.72 & - & 91.33 & 0.18 & 0.16 & 1.23 & 0.65 \\
\hline Red Sea & Rass Garp M9 & 0.50 & 0.86 & - & 76.78 & 0.10 & 0.06 & 6.68 & 0.72 \\
\hline Sinai & Empradoor M10 & 0.67 & 0.36 & 0.62 & 67.95 & 0.05 & 0.23 & 1.01 & 0.18 \\
\hline Sinai & Karara M11 & - & 0.83 & - & 63.72 & 0.29 & 0.06 & 2.03 & 1.02 \\
\hline Aswan & Zandpyaa M13 & 8.44 & - & 1.37 & - & 0.10 & 0.07 & 34.93 & - \\
\hline Qena & Green Qena M14 & 14.35 & 1.59 & 12.41 & 3.76 & 0.25 & 0.09 & 26.42 & 13.18 \\
\hline Region & Commercial name, Element & $\mathrm{Mg}$ & \multicolumn{2}{|c|}{$\mathrm{Na}$} & $\mathrm{K}$ & $\mathrm{Zn}$ & $\mathrm{U}^{*}$ & $\mathrm{Th}^{*}$ & $\mathrm{~K}^{*}$ \\
\hline Suez Golf & Glalla E1Suez M1 & 0.15 & \multicolumn{2}{|c|}{-} & - & 0.92 & 3.20 & 1.47 & 0.15 \\
\hline Sinai & Alpastar Odysyi M2 & 1.03 & \multicolumn{2}{|c|}{3.63} & - & 0.19 & 3.14 & 1.36 & 0.20 \\
\hline Sinai & AswadPrown M3 & 1.36 & \multicolumn{2}{|c|}{3.44} & - & 0.05 & 3.46 & 2.19 & 1.11 \\
\hline Suez Golf & Glalla KasKremy M4 & 0.83 & \multicolumn{2}{|c|}{4.44} & - & 0.39 & 8.08 & 1.29 & 0.15 \\
\hline Suez Golf & Red Glalla M5 & 0.67 & \multicolumn{2}{|c|}{3.40} & - & 0.87 & 3.02 & 1.08 & 0.13 \\
\hline Sinai & Prechaa M6 & 0.93 & \multicolumn{2}{|c|}{3.50} & - & 0.27 & 4.38 & 1.38 & 0.13 \\
\hline Sinai & Khatemaa M7 & 1.11 & \multicolumn{2}{|c|}{3.12} & - & 0.27 & 3.03 & 1.47 & 0.17 \\
\hline Sinai & Kerstin M8 & 1.18 & \multicolumn{2}{|c|}{4.31} & - & - & 7.75 & 1.70 & 0.22 \\
\hline Sinai & Karara M11 & 29.83 & \multicolumn{2}{|c|}{2.22} & - & - & 3.23 & 0.97 & 0.16 \\
\hline Sinai & Kerstin South M112 & 4.01 & \multicolumn{2}{|c|}{1.46} & 1.14 & - & 6.14 & 2.31 & 0.18 \\
\hline Aswan & Zandpyaa M13 & 44.49 & \multicolumn{2}{|c|}{8.65} & 0.93 & 1.02 & 3.43 & 0.88 & 0.26 \\
\hline Qena & Green Qena M14 & 21.61 & \multicolumn{2}{|c|}{2.63} & 1.80 & 1.90 & 3.56 & 1.38 & 4.62 \\
\hline
\end{tabular}


X-ray diffraction technique has been used to investigate the structure and characteristics of the prepared samples. The obtained X-ray diffraction patterns of the investigated powder samples are shown in Figure 3. The XRD analysis showed three main peaks characteristic of calcium minerals, while other minor phases are attributed to metallic impurities .This figure reveals that for Table 3, there is diffraction peaks; the samples are found in the crystalline states. On the contrary, the spectra of X-ray diffraction pattern of samples M (1-14) exhibits sharp diffraction lines $(2 \theta \approx 27$ to 30 ) which belong to crystalline $(\mathrm{Ca})$. This means that this sample is crystalline.

X-ray diffraction (XRD) analyses of (14) samples taken from Egypt where the solid material proportion was considerably high revealed that calcite mineral was the main component for mixed, grey, yellow, green, black and white colored samples [27].
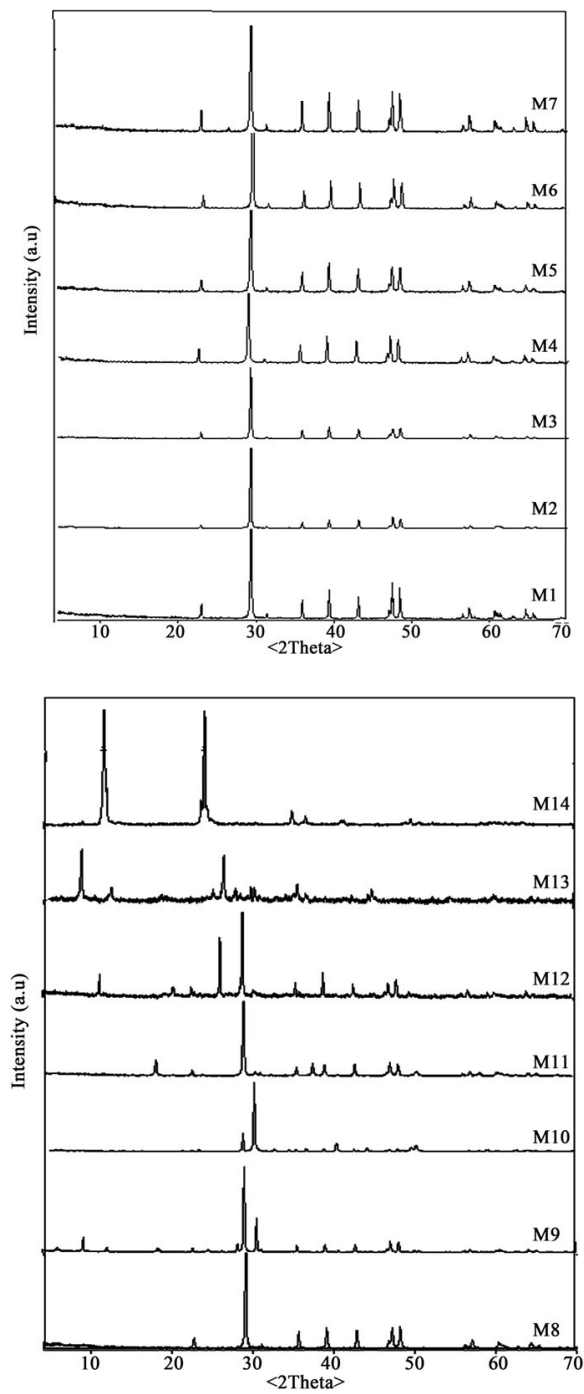

Figure 3. XRD of Marble Samples.
The morphology of the pure sample is shown in Figure 4. Exhibit a continuous grain growth; meanwhile, the crystalline phase does not propagate homogeneously as it contains a mixture of amorphous and crystalline regions. The changes continue, with change material, resulting in amorphous-crystal phase change. The image of the (1-14) marble powder or synthetic calcium carbonate $\left(\mathrm{CaCO}_{3}\right)$ powder materials shows individual grains, which are irregular in size \& shape, and separated by well defined inter-grain boundaries. The droplets are substantially spherical and have convex surfaces for samples M (1-8). Similar images have been observed for other sample M (9-14), where the image reflects the shape of island structures. As the calcium carbonate increases, still amorphous except for few grains that became crystallized owing to their polarization or orientation under the irradiation process.
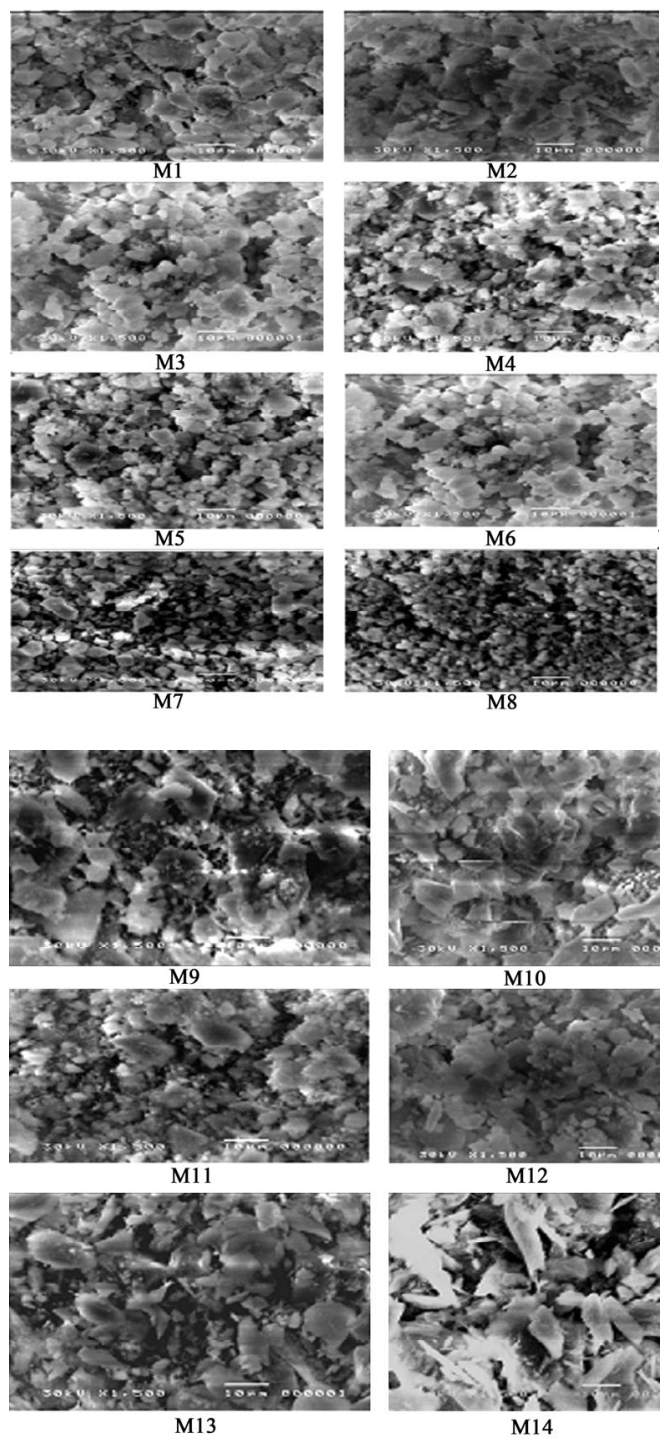

Figure 4. SEM of marble samples. 


\section{CONCLUSIONS}

The activity concentrations in studied Marble tiles of wide use locally in Egypt in the building industry were determined, employing high-resolution gamma-ray spectroscopy. The activity concentrations of ${ }^{226} \mathrm{Ra},{ }^{232} \mathrm{Th}$ and ${ }^{40} \mathrm{~K}$ in the Marble samples have been found to ranged from $(3.57 \pm 0.64)$ to $(9.37 \pm 1.8) \mathrm{Bq} \cdot \mathrm{kg}^{-1}$ for ${ }^{232} \mathrm{Th}$, $(37.6 \pm 1.7)$ to $(100.54 \pm 3.2) \mathrm{Bq} \mathrm{kg}^{-1}$ for ${ }^{226} \mathrm{Ra}$ and $(30.68 \pm 81.1)$ to $(1196 \pm 4.9) \mathrm{Bq} \cdot \mathrm{kg}^{-1}$ for ${ }^{40} \mathrm{~K}$. According to recommendation no. 112 issued by the European Commission, any actual decision on restricting the use of a material should be based on a separate dose assessment. Such an assessment should be based on scenarios where the material is used in a typical way for the type of material in question. As it can be seen from Table 2, the mean radioactive concentrations of ${ }^{226} \mathrm{Ra},{ }^{232} \mathrm{Th}$ and ${ }^{40} \mathrm{~K}$ of the Marble samples of this study are generally safe, just like that of all other Marble sample referred to in the literature. The natural radioactivity levels for the Marble tiles measured in this study are comparable to those measured on a worldwide scale. Apart from the previously cited three Marbles, it is concluded: that all of the studied materials are safe to use for dwelling construction. It should be emphasized that accurate information concerning the commercial names and origins of these Marbles is very important because simple mistakes with respect to that can produce serious economical and social consequences in the stone market sector.

\section{REFERENCES}

[1] Organization for Economic Cooperation and Development (1979) Exposure to radiation from the natural radioactivity in building materials (OECD, Paris). Report by a Group of Experts of the OECD, Nuclear Energy Agency.

[2] Wedepohl, K.H. (1995) The composition of the continental crust. Geochimica et Cosmochimica Acta, 59, 1217-1232. doi:10.1016/0016-7037(95)00038-2

[3] Menager, M.T. Heath, M.J., Ivanovich, M., Montjotin, C., Barillon, C.R., Camp, J. and Hasler, S.E. (1993) Migration of uranium from uranium-mineralized fractures into the rock matrix in Marble: Implications for radionuclide transport around a radioactive waste repository. 4th International Conference of Chemistry and Migration Behaviour of Actinides and Fission Products in the Geosphere, Charleston, 12-17 December 2993, 47-83.

[4] Pavlidou, S., Koroneos, A., Papastefanou, C., Christofides, G., Stoulos, S. and Vavelides, M. (2006) Natural radioactivity of Marbils used as building materials. Journal of Environmental Radioactivity, 89, 48-60. doi:10.1016/j.jenvrad.2006.03.005

[5] Tzortzis, M., Tsertos, H., Christofides, S. and Christodoulides, G. (2003) Gamma radiation measurements and dose rates in commercially-used natural tiling rocks
(Marbels). Journal of Environmental Radioactivity, 70, 223-235. doi:10.1016/S0265-931X(03)00106-1

[6] United Nations Scientific Committee on the Effects of Atomic Radiation (UNSCEAR) (1993) Exposures from natural sources of radiation. United Nations, New York, Annex A, A/Ac., 82/R.

[7] United Nations Scientific Committee on the Effects of Atomic Radiation (UNSCEAR) (2000) Sources, effects and risks of ionizing radiation. United Nations, New York.

[8] Keller, G., Folkerts, K.H. and Muth, H. (1987) Discussing possible standards of natural radioactivity in building materials. Radiation and Environmental Biophysics, 26, 143-150. doi:10.1007/BF01211408

[9] Savidou, A., Raptis, C. and Kritidis, P. (1996) Study of natural radionuclides and radon emanation in bricks used in the Attica region, Greece. Environmental Radioactivity, 31, 21-28.

[10] ICRP (1991) Recommendations of the international commission on radiological protection. ICRP Publication 60, Pergamon Press, Oxford.

[11] Lavi, N., Groppi, F. and Alfassi, Z.B. (2004) On the measurement of $40 \mathrm{~K}$ in natural and synthetic materials by the method of high resolution gamma-ray spectrometry. Radiation Measurements, 38,139-143. doi:10.1016/j.radmeas.2003.11.005

[12] Akhtar, N., Tufail, M., Ashraf, M., Mohsin, A. and Iqbal, M. (2005) Measurements of environmental radioactivity for estimation of radiation exposure from saline soil of Labore, Pakistan. Radiation Measurements, 39, 11-14.

[13] European Commission (1999) Radiological protection principles concerning the natural radioactivity of building materials. Radiation Protection 112.

[14] Guan, K.N., Yu, X.J., Stoks, M.J. and Young, E.C. (1992) The assessment of natural radiation dose committed to the Hong Kong people. Journal of Environmental Radioactivity, 17, 931.

[15] Beretka, J. and Mathew, P.J. (1985) Natural radioactivity of Australian building materials, industrial wastes and by-products. Health Physics, 48, 87-95. doi:10.1097/00004032-198501000-00007

[16] Hayumbu, P., Zaman, M.B., Lubaba, N.C.H., Munsanje, S.S. and Nuleya, D. (1995) Natural radioactivity in Zambian building materials collected from Lusaka. Journal of Radioanalytical and Nuclear Chemistry, 199, 229-238. doi:10.1007/BF02162371

[17] Harb, S. (2008) Natural radioactivity and external gamma radiation exposure at the coastal red sea in Egypt. $R a$ diation Protection Dosimetry, 130, 376-384. doi:10.1093/rpd/ncn064

[18] Taskin, H., Karavus, M., Ay, P., Topuzoglu, A., Hindiroglu, S. and Karahan, G. (2009) Radionuclide concentrations in soil and lifetime cancer risk due to the gamma radioactivity in Kirklareli, Turkey. Journal of Environmental Radioactivity, 100, 49-53. doi:10.1016/j.jenvrad.2008.10.012

[19] Amrani, D. and Tahtat, M. (2001) Natural radioactivity in Algerian building materials. Applied Radiation and Isotopes, 54, 687-689. doi:10.1016/S0969-8043(00)00304-3

[20] Ngachina, M., Garavagliac, M., Giovanic, C., Kwato, N.M.G. and Nourreddined, A. (2007) Assessment of 
natural radioactivity and associated radiation hazards in some Cameroonian building materials. Radiation Measurements, 42, 61-67. doi:10.1016/j.radmeas.2006.07.007

[21] Ahmad, M.N. and Hussein, A.J.A. (1997) Natural radioactivity in Jordanian building materials and the associated radiation hazards. Journal of Environmental Radioactivity, 39, 9-22.

[22] Bou-Rabee, F. and Bem, H. (1996) Natural radioactivity in building materials utilized in the state of Kuwait. Journal of Radioanalytical and Nuclear Chemistry, 213, 143-149. doi:10.1007/BF02165246

[23] Ahmed, N.K. (2005) Measurement of natural radioactivity in building materials in Qena city, Upper Egypt. Journal of Environmental Radioactivity, 83, 91-99. doi:10.1016/j.jenvrad.2005.03.002
[24] Al-Saleh, F.S. and Al-Berzan, B. (2007) Measurements of natural radioactivity in some kinds of marble and granite used in Riyadh Region. Journal of Nuclear and Radiation Physics, 2, 25-36.

[25] IAEA (2003) Guide lines for radioelement mapping using gamma ray spectrometry data. International Atomic Energy Agency, Vienna.

[26] Khrbish, Y.S., Abugassa, I.O., Benfaid, N. and Bashir, A.A. (2007) Instrumental neutron activation analysis for the elemental analysis of cement. Journal of Radioanalytical and Nuclear Chemistry, 271, 63-69. doi:10.1007/s10967-007-0107-3

[27] Ohama, Y. (1998) Polymer-based admixtures. Cement and Concrete Composites, 20, 189-212. doi:10.1016/S0958-9465(97)00065-6 